\title{
Genomic Diversity of Several Corynebacterium Species Identified by Amplification of the 16S-23S rRNA Gene Spacer Regions
}

\author{
DOMINIQUE AUBEL, ${ }^{*}$ FRANÇOIS N. R. RENAUD, AND JEAN FRENEY \\ DERBA, UPR ES EA 1655, Laboratoire de Bactériologie, Faculté René Laennec, Lyon, France
}

\begin{abstract}
In order to investigate whether 16S-23S ribosomal DNA (rDNA) spacer region length polymorphisms are suitable for identification of Corynebacterium strains at the species level, the 16S-23S rDNA intergenic spacer region lengths of 128 strains belonging to 11 Corynebacterium species were studied by a PCR-based method. The lengths of the 16S-23S rDNA spacer regions varied from 394 to $585 \mathrm{bp}$, fragment lengths which are similar to those described for other genera. A single PCR profile was obtained for each of the following species: Corynebacterium renale, Corynebacterium urealyticum, Corynebacterium diphtheriae, Corynebacterium ulcerans, Corynebacterium pseudodiphtheriticum, and Corynebacterium kutscheri. In contrast, two and three PCR patterns were detected for Corynebacterium minutissimum, Corynebacterium striatum, Corynebacterium amycolatum, and Corynebacterium jeikeium, suggesting that genomic heterogeneity occurs in these four species. The 16S-23S rDNA spacer region length polymorphisms allowed us to discriminate among $C$. minutissimum, $C$. striatum, and $C$. amycolatum, three species that are frequently isolated and misidentified in clinical laboratories. Type strain Corynebacterium xerosis ATCC 373, which exhibited a PCR pattern similar to that of $C$. amycolatum strains classified in PCR group I, could nevertheless be discriminated from PCR group II (C. amycolatum) strains, as well as $C$. minutissimum and $C$. striatum strains. Type strain $C$. xerosis ATCC 373 and $C$. amycolatum strains classified in PCR group I could not be distinguished from strains belonging to $C$. diphtheriae, $C$. ulcerans, and $C$. pseudodiphtheriticum. The lipophilic species $C$. urealyticum and $C$. jeikeium, which are frequently encountered in clinical specimens, could be clearly distinguished from each other by this method. The use of $16 \mathrm{~S}-23 \mathrm{~S}$ spacer region length data determined by PCR-mediated amplification is suitable for identification of several Corynebacterium species. This rapid and easy method may be a useful identification tool for clinical microbiologists.
\end{abstract}

Clinical laboratories frequently isolate Corynebacterium species from clinical specimens, and consequently interest in the genus Corynebacterium is increasing (16). This genus was initially created for the etiologic agent of diphtheria, Corynebacterium diphtheriae (8). This species was later found to also be involved in cutaneous infections (21), endocarditis $(30,43)$, septicemia (19), and osteomyelitis (37). It was thought that diphtheria had almost been eliminated by widespread immunization, but since the 1990s the number of cases of diphtheria reported from Eastern Europe, particularly Russia, has increased (6). Furthermore, cases of diphtheria have been reported recently in Norway $(27,32)$ and Italy $(48)$. Nevertheless, the human pathogen $C$. diphtheriae is infrequently encountered in clinical specimens compared to other Corynebacterium species, such as Corynebacterium amycolatum, Corynebacterium minutissimum, Corynebacterium striatum, Corynebacterium jeikeium, Corynebacterium urealyticum, and Corynebacterium pseudodiphtheriticum (16). Endocarditis, septicemia, pneumonia, and urinary tract infections are the most common infections caused by these species $(7,10,16)$. Additional species or groups of corynebacteria recognized by the Centers for Disease Control and Prevention have also been found in clinical samples, but they are infrequently isolated, and the roles that some of them play in diseases are still unknown (16).

Various phenotypic and genotypic methods have been used to identify Corynebacterium species. These methods include biochemical tests performed by conventional methods (28) or with the API Coryne system $(14,18)$, cell wall analysis by thin-layer chromatography (2) or high-performance liquid

\footnotetext{
* Corresponding author. Present address: I.U.T. A, Lyon 1, Département de Biologie Appliquée, Laboratoire de bactériologie, 43 Boulevard du 11 novembre 1918, 69622 Villeurbanne cedex, France. Phone: 33 (0) 4726920 63. E-mail: renaud@cimac-res.univ-lyon1.fr.
}

chromatography (11), and restriction analysis of the amplified 16S ribosomal DNA (rDNA) (45). However, some of these techniques are not suitable for routine use in clinical laboratories and are reserved for reference laboratories. Recent data have shown that clinical microbiologists frequently confuse $C$. amycolatum, $C$. minutissimum, $C$. striatum, and Corynebacterium xerosis $(2,15,16,49,50)$. Misidentification of these organisms is not surprising, particularly when identification is based on the results obtained with the API Coryne system, a system which does not yet contain data for $C$. amycolatum in its database.

Analysis of the length polymorphism generated by PCRmediated amplification of the $16 \mathrm{~S}-23 \mathrm{~S}$ rDNA spacer regions has been used previously for rapid identification of species belonging to the genera Salmonella, Staphylococcus, Listeria, and Legionella $(24,26)$. Moreover, this method seems to be a good tool for epidemiological studies, as demonstrated with Burkholderia (Pseudomonas) cepacia (29) and Clostridium difficile (5). The purposes of this study were to investigate the length polymorphisms in the $16 \mathrm{~S}-23 \mathrm{~S}$ rDNA intergenic spacer regions of Corynebacterium strains and to determine whether this method is a useful identification tool for clinical microbiologists.

\section{MATERIALS AND METHODS}

Bacterial strains. This study was carried out with 128 Corynebacterium strains, including 109 human clinical isolates and 19 reference strains. The clinical strains were either isolated from patients hospitalized in Lyon (France) or obtained from the Laboratoire des Identifications Bactériennes (Institut Pasteur, Paris, France) and the Institut de Bactériologie (Faculté de Médecine, Strasbourg France). The reference strains were obtained from the American Type Culture Collection (ATCC) (Rockville, Md.), the National Collection of Type Cultures (NCTC) (London, United Kingdom), the Collection of Institut Pasteur (CIP) (Paris, France), the National Collection of Dairy Organisms (NCDO) (Reading, United Kingdom), and the Centers for Disease Control and Prevention (CDC) (Atlanta, Ga.). The following 11 Corynebacterium species were included in this study: $C$. diphtheriae (23 nontoxinogenic clinical isolates and 5 reference strains, 
strains CIP 52.112 [biotype mitis], CIP 100721 [type strain; biotype mitis], CIP A98 [biotype mitis], CIP A99 [biotype intermedius], and CIP A102 [Park-Williams no. 8; biotype gravis]); C. urealyticum (11 clinical isolates and 2 reference strains, strains ATCC 43042 [type strain] and ATCC 43043); C. jeikeium (25 clinical isolates and reference strain CIP 103337 [type strain]); C. pseudodiphtheriticum ( 3 clinical isolates and reference strain ATCC 7091 [type strain]); Corynebacterium renale ( 2 clinical isolates and 2 reference strains, strains NCTC 7188 and NCTC 7448 [type strain]); Corynebacterium ulcerans (4 clinical isolates and 3 reference strains, strains NCTC 7907, NCDO 1924, and NCDO 1896); Corynebacterium kutscheri ( 2 clinical isolates and reference strain NCTC 11138); C. minutissimum (2 clinical isolates and reference strain ATCC 23348 [type strain]); C. striatum (14 clinical isolates and 2 reference strains, strains NCTC 764 [type strain] and CDC 5333); C. xerosis (reference strain ATCC 373 [type strain]); and C. amycolatum (23 clinical isolates).

Culture conditions and biochemical tests. Corynebacterium strains were grown in an atmosphere containing $10 \% \mathrm{CO}_{2}$ at $37^{\circ} \mathrm{C}$ for $24 \mathrm{~h}$ either on Columbia agar (bioMérieux, Marcy l'Etoile, France) supplemented with 5\% (vol/vol) sheep blood (bioMérieux) or (for C. urealyticum and C. jeikeium strains, which require lipid for optimal growth $[25,40])$ on Columbia agar supplemented with $5 \%$ (vol/vol) sheep blood and 1\% (vol/vol) Tween 80 (polyoxyethylene sorbitan monooleate; Merck, Darmstadt, Germany).

The Corynebacterium strains were identified by the conditions which resulted in growth, by colony morphology, by Gram staining, and by biochemical tests with the API Coryne system (bioMérieux) and conventional methods. Since the commercial API Coryne system was not able to discriminate among $C$. minutissimum, C. xerosis, C. striatum, and C. amycolatum (16), all of the strains initially identified as $C$. minutissimum, $C$. xerosis, and $C$. striatum by the API Coryne system were checked by using the identification schemes recently described by Zinkernagel et al. (50), Funke et al. $(15,16)$, Wauters et al. (49). Nitrate reductase production was tested by using Trypticase soy broth supplemented with $2 \mathrm{~g}$ of $\mathrm{NaNO}_{3}$ per liter. After incubation for 24 to $48 \mathrm{~h}$ at $37^{\circ} \mathrm{C}$, the presence of nitrite in the medium was detected by adding sulfanilic acid $(0.8 \%$, wt $/ \mathrm{vol}$; Merck) in $5 \mathrm{~N}$ acetic acid (Merck) and $\mathrm{N}$ - $\mathrm{N}$-dimethyl-1-naphthylamine $(0.6 \%$, $\mathrm{wt} / \mathrm{vol}$; Merck) in $5 \mathrm{~N}$ acetic acid. A pink color indicated that nitrite was present; zinc powder, which reduces nitrate in nitrite, was added when no color was observed. Acid production from sucrose and maltose and $\alpha$-glucosidase synthesis were determined by using chromogenic substrate tablets (Diatabs; Rosco, Taastrup, Denmark) incubated in $0.5 \mathrm{ml}$ of a bacterial suspension with a turbidity equivalent to the turbidity of a McFarland no. 6 standard for 4 to $24 \mathrm{~h}$ at $37^{\circ} \mathrm{C}$. The tyrosine hydrolysis test was performed on nutrient agar containing $0.5 \%$ (wt/vol) L-tyrosine. DNase activity was tested on DNA agar plates (bioMérieux) by flooding the plates with a $1 \mathrm{M}$ hydrochloric acid solution after 4 days of incubation at $37^{\circ} \mathrm{C}$. Mycolic acids were detected as described by Minnikin et al. (34).

PCR amplification of the 16S-23S rDNA intergenic spacer regions. The oligonucleotide primers used for PCR amplification of the 16S-23S spacer regions have been described previously (26). Primer G1 (5'-GAAGTCGTAACAAGG$\left.3^{\prime}\right)$, which was selected from a highly conserved region in the 16S RNA gene, is located about 30 to 40 nucleotides upstream from the spacer region. Primer L1 (5'-CAAGGCATCCACCGT-3') contained the most conserved $23 \mathrm{~S}$ sequence and is located about 20 nucleotides downstream from the spacer boundary.

A 1- $\mu$ l loopful of bacteria grown on Columbia agar containing sheep blood was resuspended in $100 \mu \mathrm{l}$ of distilled water. The bacterial suspension was incubated at $95^{\circ} \mathrm{C}$ for $15 \mathrm{~min}$ and centrifuged for $2 \mathrm{~min}$ at $7,600 \times \mathrm{g}$. PCR amplification was carried out in a 100- $\mu$ l (total volume) mixture containing $5 \mu l$ of the supernatant and $95 \mu \mathrm{l}$ of a solution which contained $0.5 \mu \mathrm{M}$ primer $\mathrm{G} 1,0.5 \mu \mathrm{M}$ primer $\mathrm{L} 1$, each of the four deoxynucleoside triphosphates (Pharmacia Biotech, Uppsala, Sweden) at a concentration of $200 \mu \mathrm{M}, 10 \mu \mathrm{l}$ of Gene Amp 10× PCR buffer (Perkin-Elmer, Norwalk, Conn.), and $2.5 \mathrm{U}$ of AmpliTaq DNA polymerase (Perkin-Elmer).

PCR amplification was performed with a Crocodile II apparatus (Appligene, Illkirch, France). After an initial denaturation step consisting of 2 min at $94^{\circ} \mathrm{C}$ the DNA was amplified for 25 cycles. Each cycle consisted of 1 min at $94^{\circ} \mathrm{C}$ (denaturation), $7 \mathrm{~min}$ at $47^{\circ} \mathrm{C}$ (annealing), and $2 \mathrm{~min}$ at $72^{\circ} \mathrm{C}$ (elongation). The last cycle was followed by a 7 -min extension step at $72^{\circ} \mathrm{C}$. To check that no contamination had occurred, a negative control containing distilled water instead of template DNA was included in each experiment. To investigate the reproducibility of the band pattern obtained by PCR amplification, two independent PCR amplifications were performed for each strain included in this study.

Analysis of PCR products. The amplified products were analyzed by electrophoresis in $2 \%$ (wt/vol) agarose gels (High Resolution; Sigma Chemical Co., St. Louis, Mo.) containing ethidium bromide $(\mathrm{EtBr})(0.5 \mu \mathrm{g} / \mathrm{ml})$ in $1 \times$ Tris-borateEDTA buffer (33). The PCR products were visualized by UV fluorescence. To calculate the lengths of amplicons, DNA molecular weight marker VI (Boehringer, Mannheim, Germany) was included on each gel in the edge lanes and every five lanes. To assess PCR reproducibility, the two separate PCR amplification mixtures prepared for each strain were run side by side on the same gel. The gels were photographed and scanned. The lengths of PCR products were calculated automatically by using the RestrictoScan and RestrictoTyper programs (P. A. D. Grimont, Taxolab, Institut Pasteur, Paris, France), and a mean size ( \pm standard deviation) was calculated for each strain. The mobility size errors from gel to gel were assessed with 14 Corynebacterium strains for which
TABLE 1. Evaluation of experimental conditions

\begin{tabular}{lll}
\hline & \multicolumn{2}{c}{$\begin{array}{c}\text { Mean size of amplified } \\
\text { fragments } \pm \text { SD (bp) }\end{array}$} \\
\cline { 2 - 3 } \multicolumn{1}{c}{ Taxon } & $\begin{array}{c}\text { After running on } \\
\text { the same gel }\end{array}$ & $\begin{array}{c}\text { After running on } \\
\text { two different gels }\end{array}$ \\
\hline C. renale & $396 \pm 1$ & $394 \pm 1$ \\
C. urealyticum & $440 \pm 1$ & $438 \pm 3$ \\
C. diphtheriae & $438 \pm 2$ & $447 \pm 5$ \\
C. ulcerans & $462 \pm 2$ & $459 \pm 1$ \\
C. pseudodiphtheriticum & $461 \pm 1$ & $468 \pm 0$ \\
C. kutscheri & $493 \pm 2$ & $502 \pm 3$ \\
C. amycolatum PCR group I & $459 \pm 0$ & $460 \pm 3$ \\
C. amycolatum PCR group II & $479 \pm 1$ & $475 \pm 6$ \\
C. striatum PCR group I & $498 \pm 1$ & $497 \pm 5$ \\
C. striatum PCR group II & $543 \pm 1,500 \pm 1$ & $535 \pm 3,491 \pm 5$ \\
C. minutissimum PCR group II & $539 \pm 1$ & $537 \pm 9$ \\
C. jeikeium PCR group I & $490 \pm 0$ & $480 \pm 1$ \\
C. jeikeium PCR group II & $522 \pm 1$ & $519 \pm 4$ \\
C. jeikeium PCR group III & $534 \pm 1$ & $535 \pm 5$ \\
\hline
\end{tabular}

${ }^{a}$ Values are the means \pm standard deviations $(n=2)$ calculated from two separate amplifications.

${ }^{b}$ PCR groups are described in Table 2 and in the text.

both independent amplification products were run not only side by side on the same gel, but also on two different gels; the mean sizes ( \pm standard deviations) were calculated for both experiments and compared.

\section{RESULTS}

Evaluation of experimental conditions. The 16S-23S rDNA intergenic spacer regions were amplified twice for each Corynebacterium strain included in this study. The separate amplicons obtained for each strain were run side by side on the same gel, and the mean sizes and standard deviations were calculated. The standard deviations did not exceed $2 \mathrm{bp}$, indicating that the reproducibility of the method was good (Table 1 ). For 14 Corynebacterium strains representing each species included in this study and each PCR group (see below) except $C$. xerosis and $C$. minutissimum PCR group II, the independent amplicons were run side by side on the same gel, as well as on two different gels. A comparison of mean sizes that were calculated after the amplicons were run on the same gel and on two different gels revealed a maximum difference of $10 \mathrm{bp}$ (Table 1). We concluded that the level of uncertainty in the calculated sizes of amplification products did not exceed $2 \%$. In some cases, particularly for strains belonging to $C$. diphtheriae, $C$. amycolatum, $C$. minutissimum, and $C$. striatum, weaker and unreproducible amplification products in the 600 - to $1,500-\mathrm{bp}$ size range were also observed. These fragments could be generated with primer L1 alone but not with primer G1 alone. Because these fragments were unreproducible, they were not considered in the comparison of amplification profiles.

PCR patterns of Corynebacterium strains. The lengths of PCR products are summarized in Table 2 , and representative examples of the $16 \mathrm{~S}-23 \mathrm{~S}$ amplification products are shown in Fig. 1.

A single amplified fragment, referred to as the primary fragment in Table 2, was obtained for each strain belonging to $C$. renale, $C$. urealyticum, $C$. diphtheriae, C. ulcerans, C. pseudodiphtheriticum, and $C$. kutscheri. Since the PCR product lengths were identical for all of the strains belonging to the same species, a unique PCR group was defined for each of these six species. As shown in Table 2, the mean size of the amplified fragment varied from $394 \pm 3$ bp for $C$. renale to $499 \pm 7$ bp for 
TABLE 2. Sizes of the 16S-23S rDNA spacer regions of Corynebacterium strains

\begin{tabular}{|c|c|c|c|}
\hline \multirow{2}{*}{ Taxon (reference strain) ${ }^{a}$} & \multirow{2}{*}{$\begin{array}{l}\text { No. of } \\
\text { strains }\end{array}$} & \multicolumn{2}{|c|}{$\begin{array}{l}\text { Mean size of amplified } \\
\text { fragments } \pm \mathrm{SD}(\mathrm{bp})^{b}\end{array}$} \\
\hline & & $\begin{array}{c}\text { Primary } \\
\text { fragment(s) }\end{array}$ & $\begin{array}{l}\text { Weaker } \\
\text { fragment }\end{array}$ \\
\hline C. renale & 4 & $394 \pm 3$ & \\
\hline C. urealyticum & 13 & $440 \pm 4$ & \\
\hline C. diphtheriae & 28 & $446 \pm 4$ & \\
\hline C. ulcerans & 7 & $454 \pm 8$ & \\
\hline C. pseudodiphtheriticum & 4 & $463 \pm 3$ & \\
\hline C. kutscheri & 3 & $499 \pm 7$ & \\
\hline C. xerosis (ATCC $373^{\mathrm{T}}$ ) & 1 & 455 & \\
\hline C. amycolatum PCR group I & 15 & $463 \pm 5$ & $488^{c}$ \\
\hline C. amycolatum PCR group II & 8 & $476 \pm 4,493^{c}$ & \\
\hline $\begin{array}{l}\text { C. striatum PCR group I } \\
\left(\text { NCTC } 764^{\mathrm{T}}\right)\end{array}$ & 8 & $497 \pm 5$ & $538^{c}$ \\
\hline $\begin{array}{l}\text { C. striatum PCR group II } \\
\text { (CDC 5333) }\end{array}$ & 8 & $539 \pm 4$ & $489 \pm 6^{d}$ \\
\hline $\begin{array}{l}\text { C. minutissimum PCR group I } \\
\left(\text { ATCC } 23348^{\mathrm{T}}\right)\end{array}$ & 1 & 585,566 & \\
\hline C. minutissimum PCR group II & 2 & $539 \pm 1$ & $573^{c}$ \\
\hline $\begin{array}{l}\text { C. jeikeium PCR group I } \\
\left(\text { CIP } 103337^{\mathrm{T}}\right)\end{array}$ & 21 & $494 \pm 6$ & \\
\hline C. jeikeium PCR group II & 4 & $521 \pm 2$ & $537^{c}$ \\
\hline C. jeikeium PCR group III & 1 & 534 & \\
\hline
\end{tabular}

${ }^{a}$ The reference strain of a species is indicated only when there were several PCR groups in the species.

${ }^{b}$ Values are the means \pm standard deviations $(n=2$ to 28$)$; two separate amplifications were performed for each strain

${ }^{c}$ A PCR product was obtained for only one strain.

${ }^{d}$ For two strains, this fragment had the same fluorescence intensity in EtBrstained agarose gels as the primary fragment.

C. kutscheri. Strain ATCC $373^{\mathrm{T}}$, a representative of $C$. xerosis, also produced a single PCR fragment, at $455 \mathrm{bp}$.

The strains of $C$. amycolatum, $C$. striatum, $C$. minutissimum, and $C$. jeikeium did not produce identical PCR profiles. Con- sequently, the strains belonging to $C$. amycolatum, $C$. striatum, and $C$. minutissimum were divided into two PCR groups and the strains belonging to $C$. jeikeium were divided into three groups on the basis of the number of PCR products and their lengths (Table 2). A total of $15 \mathrm{C}$. amycolatum strains $(65 \%)$ were classified in PCR group I, and the other 8 clinical isolates (35\%) were classified in PCR group II. All of the PCR group I and II strains except two produced a single amplified fragment, at $463 \pm 5$ and $476 \pm 5 \mathrm{bp}$, respectively. An additional fragment that was 488 to $493 \mathrm{bp}$ long was produced by two strains, one belonging to PCR group I and the other belonging to PCR group II. This additional fragment is referred to in Table 2 as a primary fragment as its fluorescence intensity in EtBr-stained agarose gels was identical to that of the other amplified fragment.

C. striatum strains produced a primary amplified fragment that was either $497 \pm 5$ bp long (C. striatum PCR group I) or $539 \pm 4$ bp long (C. striatum PCR group II). It should be emphasized that an additional fragment $(489 \pm 6 \mathrm{bp})$ with equal or less intensity after EtBr staining was observed with all of the strains classified in PCR group II. An additional 538-bp fragment was generated by only one strain belonging to PCR group I. Type strain NCTC 764 and seven clinical isolates (50\% of the C. striatum strains) belonged to PCR group I, whereas reference strain CDC 5333 and seven other clinical isolates were classified in PCR group II.

16S-23S spacer region amplification from C. minutissimum type strain ATCC 23348 generated two PCR products that exhibited identical intensities after EtBr staining; these products were at 585 and $566 \mathrm{bp}$. Both clinical isolates belonging to this species were classified in a separate group (PCR group II) since the lengths of the amplicons generated were $539 \pm 4 \mathrm{bp}$; one of these strains produced an additional fragment at $573 \mathrm{bp}$.

With the exception of one strain which exhibited two PCR products, all of the $C$. jeikeium strains $(96 \%)$ produced a single amplified fragment at either $494 \pm 6$ bp $(C$. jeikeium PCR group I), $521 \pm 2$ bp (C. jeikeium PCR group II), or 534 bp (C.

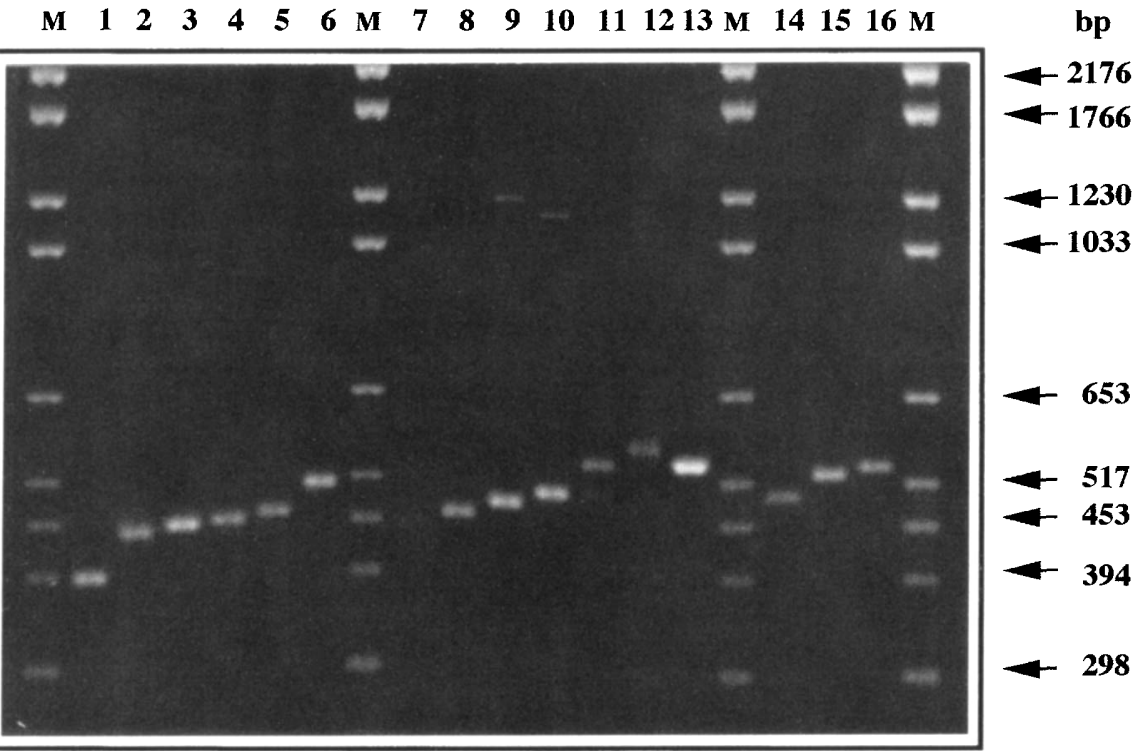

FIG. 1. Agarose gel electrophoresis of PCR-amplified 16S-23S rDNA spacer regions from Corynebacterium strains. Lane 1, C. renale NCTC 7188; lane 2, C. urealyticum ATCC 43042 ${ }^{\mathrm{T}}$; lane 3 , C. diphtheriae CIP $100721^{\mathrm{T}}$; lane 4, C. ulcerans NCTC 7907; lane 5, C. pseudodiphtheriticum ATCC 7091; lane 6, C. kutscheri NCTC 11138; lane 7, C. xerosis ATCC $373^{\mathrm{T}}$; lane 8, C. amycolatum PCR group I; lane 9, C. amycolatum PCR group II; lane 10, C. striatum NCTC 764 ${ }^{\mathrm{T}}$ PCR group I; lane 11, C. striatum CDC 5333 PCR group II; lane 12, C. minutissimum ATCC 23348 ${ }^{\mathrm{T}}$ PCR group I; lane 13, C. minutissimum PCR group II; lane 14, C. jeikeium CIP 103337 PCR group I; lane 15, C. jeikeium PCR group II; lane 16, C. jeikeium PCR group III; lanes M, molecular weight markers (DNA molecular weight marker VI). 
jeikeium PCR group III). Reference strain CIP $103337^{\mathbf{T}}$ and 20 clinical isolates ( $81 \%$ of the $C$. jeikeium strains) were classified in $C$. jeikeium PCR group I, whereas $C$. jeikeium PCR groups II and III contained four and one clinical isolates, respectively.

\section{DISCUSSION}

A PCR-based strategy for studying the length polymorphisms of the 16S-23S rDNA spacer regions has been useful for both epidemiological $(5,29)$ and taxonomic $(3,22,24,26$, 46) investigations. In this study, the $16 \mathrm{~S}-23 \mathrm{~S}$ rDNA spacer regions of 128 Corynebacterium strains representing 11 species were studied by PCR-mediated amplification by using oligonucleotide primers $\mathrm{G} 1$ and $\mathrm{L} 1$ as previously described by Jensen et al. (26).

The lengths or nucleotide sequences of the 16S-23S rDNA spacer regions of Corynebacterium strains have not been determined so far, and the numbers of rRNA operons per genome are not even known. Consequently, the lengths of amplification products could not be predicted. In this study we showed that the lengths of the 16S-23S rDNA spacer regions in the genus Corynebacterium, which varied from $394 \mathrm{bp}$ to 585 $\mathrm{bp}$, are similar to the lengths described for members of other genera $(1,4,17,20,31)$.

Six of the 11 Corynebacterium species included in this study, C. renale, C. urealyticum, C. diphtheriae, C. ulcerans, C. pseudodiphtheriticum, and $C$. kutscheri, each produced a single PCR pattern, and each profile was characterized by a single amplification product. This result supported the hypothesis that there is genomic homogeneity in these six species. $C$. diphtheriae strains have been classified, on the basis of cultural and biochemical characteristics, into four biotypes named biotypes gravis, mitis, intermedius, and belfanti (7). The results of DNA-DNA hybridization experiments suggested that biotypes mitis, gravis, and intermedius are closely related genomically, and type strain CIP 100721 (biotype mitis) exhibited more than $90 \%$ DNA similarity with strains belonging to biotypes mitis, gravis, and intermedius (41). However, the results of several investigations, which were based on analyses of DNA restriction fragment length polymorphisms with different DNA probes, such as probes for different areas of the toxin gene (35), insertion elements (38), phage attachment sites, and corynebacteriophage $\beta$ DNA (9), or an rRNA probe (12), revealed diversity among the biotypes. With the method used in this study we were not able to detect polymorphism among the $28 C$. diphtheriae strains, examined, which were isolated between 1982 to 1988 from different geographical regions and belonged to different biotypes, and consequently this method is not useful for epidemiological investigations and for identification of biotypes. Some modifications of this method, such as restriction endonuclease analysis of amplification products or amplification with another set of primers which would produce fragments that might contain polymorphisms, might allow it to be used either for differentiation of biotypes mitis, gravis, and belfanti (biotype intermedius is easily distinguished on the basis of colony morphology [16]) or for epidemiological investigations, as previously suggested for other organisms, such as Burkholderia (Pseudomonas) cepacia (29) or Clostridium difficile (5). Differentiation of the biotypes of $C$. diphtheriae has lost its relevance since the relationship between severity of disease and biotype is no longer valid (5). However, due to the resurgence of diphtheria in Eastern Europe, a PCR-based subtyping method for $C$. diphtheriae would provide significant advantages over other molecular typing methods which require DNA extraction and DNA-DNA hybridization. The results of the analysis of the rRNA gene restriction fragment polymorphisms (ribotyping) of 46 clinical isolates suggested that $C$. urealyticum represents a homogeneous taxon and that there is a low level of rRNA gene polymorphism in this species (42). This finding was supported by the results of the DNA relatedness experiments performed by Riegel et al. (40), who showed that the levels of DNA relatedness of $21 \mathrm{C}$. urealyticum strains varied from 82 to $100 \%$, which indicated that these strains constitute a tight DNA hybridization group. Our results confirmed these previously reported observations since the 13 strains studied, which were isolated between 1982 and 1988 in different hospitals, produced identical PCR profiles.

Inversely, four species, C. amycolatum, C. striatum, C. minutissimum, and $C$. jeikeium, which are frequently isolated from clinical samples, exhibited genomic heterogeneity, and several PCR profiles were obtained for each species. A higher level of heterogeneity was observed for $C$. jeikeium, for which we identified three PCR groups; two PCR groups were identified for the other three species. These results were not surprising since heterogeneity has previously been reported in each of these species. C. jeikeium, which was formerly named Corynebacterium group JK, was delineated by Jackman et al. (25) on the basis of DNA similarities and patterns of cellular proteins; however, genomic divergence from the type strain was found for some strains. Pitcher et al. (36) observed considerable rRNA gene polymorphism in this species as determined by an analysis of rRNA restriction fragments. The level of similarity for the 26 strains studied is only $30 \%$. Hindmarch et al. (23) showed by pyrolysis-mass spectrometry that $C$. jeikeium strains could be classified into six groups. This genomic diversity among $C$. jeikeium strains was later confirmed by Riegel et al. (39), who described four DNA groups by using DNA-DNA hybridization. In their study, the levels of DNA relatedness of C. jeikeium strains with type strain CIP 103337 ranged from 22 to $75 \%$. However, Riegel et al. concluded that $C$. jeikeium strains may be classified in a single taxon due to their common biochemical properties and antimicrobial susceptibility patterns. In our study, strains previously classified by these authors in DNA groups A, B, and D exhibited identical amplification patterns and were classified with 17 additional strains in C. jeikeium PCR group I, while two DNA group C strains and two other clinical isolates belonged to $C$. jeikeium PCR group II. Therefore, $16 \mathrm{~S}-23 \mathrm{~S}$ rDNA spacer region amplification with oligonucleotide primers $\mathrm{L} 1$ and $\mathrm{G} 1$ allowed us to distinguish $C$. jeikeium DNA group C from type strain CIP 103337 (DNA group $\mathrm{A}$ ) and $C$. jeikeium DNA groups $\mathrm{B}$ and $\mathrm{D}$. No biochemical test allows differentiation of the four DNA groups; nevertheless, penicillin susceptibility patterns seem to allow differentiation among the DNA groups, since type strain CIP 103337 (DNA group A) and DNA group B strains exhibit high levels of penicillin resistance (MIC, $>64 \mu \mathrm{g} / \mathrm{ml}$ ), while DNA group C and D strains exhibit low levels of penicillin resistance (MIC, 1 to $4 \mu \mathrm{g} / \mathrm{ml}$ ) (39). According to our data and the data reported by Riegel et al. (39), C. jeikeium DNA groups C and D could be differentiated from each other or from $C$. jeikeium DNA groups A and B by amplification of the 16S-23S rDNA spacer regions with primers $\mathrm{L} 1$ and $\mathrm{G} 1$ and by antimicrobial susceptibility tests. Currently, there is no method for differentiating between $C$. jeikeium DNA groups A and B.

C. amycolatum, C. striatum, and C. minutissimum were also heterogeneous according to our results. Recently, Zinkernagel et al. (50) showed that the heterogeneity within $C$. minutissimum, previously reported by Estrangin et al. (13) and Van Bosterhaut et al. (44), might be explained by misidentification of strains (C. minutissimum was confused with C. amycolatum). The results of our study of the 16S-23S rDNA spacer region lengths allow us to place $C$. minutissimum strains in two 
groups, and type strain ATCC 23348 exhibited a PCR pattern different from the PCR patterns exhibited by both clinical isolates. Both clinical strains have been identified by the scheme proposed by Zinkernagel et al. (50); thus, it is improbable that the difference from the type strain was due to misidentification of the strains. Moreover, the PCR pattern obtained for both strains was clearly different from the PCR patterns obtained for $C$. amycolatum. Thus, our results supported the hypothesis that there is genomic heterogeneity within $C$. minutissimum. The heterogeneity within $C$. striatum might also be explained by misidentification of $C$. amycolatum as $C$. striatum (16). Identification of strains with recently proposed identification schemes $(16,49,50)$ and the fact that the PCR patterns of the two species did not overlap disproved this hypothesis and confirmed the heterogeneity of $C$. striatum (7).

Identification of Corynebacterium strains to the species level, especially identification of $C$. minutissimum, C. striatum, $C$. xerosis, and $C$. amycolatum strains, is a difficult task for clinical microbiologists. This is proven by numerous reports which have shown that $C$. amycolatum is misidentified as $C$. minutissimum, $C$. striatum, or $C$.xerosis $(2,15,16,49,50)$. As shown in Table 2, amplification of the 16S-23S rDNA spacer regions with primers $\mathrm{G} 1$ and $\mathrm{L} 1$ allowed us to clearly differentiate $C$. minutissimum strains from strains belonging to the three other species. Although the strains classified as members of $C$. minutissimum PCR group II and C. striatum PCR group II produce an identical 539-bp PCR product, $C$. striatum PCR group II strains can be identified by their additional 489-bp fragment (Table 2). This PCR strategy also allowed us to distinguish $C$. striatum strains from C. amycolatum and C. xerosis. However, $C$. amycolatum and $C$. xerosis could not be differentiated clearly, since $C$. xerosis ATCC $373^{\mathrm{T}}$ produced a PCR profile similar to the PCR profiles obtained for strains classified in $C$. amycolatum PCR group I. Consequently, in this case, microbiologists should take colony morphology into account to eliminate this ambiguity (16). They should also keep in mind that C. xerosis is extremely rare in clinical samples (16). The other nonlipophilic species, $C$. renale, is rarely encountered in human clinical samples (16) and produced a PCR profile clearly distinguishable from the PCR profiles of the 10 other species included in our study. However, the strains classified in $C$. striatum PCR group I and strains belonging to $C$. kutscheri produced identical PCR profiles. However, it should be emphasized that $C$. kutscheri is pathogenic for animals but not for humans and that several biochemical characteristics can be used to differentiate these two species (16). C. diphtheriae, $C$. ulcerans, $C$. pseudodiphtheriticum, $C$. xerosis, and $C$. amycolatum (strains classified in PCR group I) produced similar PCR patterns. As mentioned above, colony morphology allows workers to distinguish C. xerosis and C. amycolatum from each other and also from C. diphtheriae, C. ulcerans, and C. pseudodiphtheriticum (16). It should be emphasized that several biochemical tests allow easy distinction of $C$. diphtheriae, $C$. ulcerans, and C. pseudodiphtheriticum (16).

The lipophilic corynebacteria $C$. jeikeium, C. urealyticum, and $C$. diphtheriae biotype intermedius, which require lipid for optimal growth, can be easily distinguished from the nonlipophilic corynebacteria on the basis of colony morphology (16). The PCR profiles of the lipophilic species C. jeikeium were clearly different from those of the other two lipophilic taxa, $C$. urealyticum and $C$. diphtheriae biotype intermedius. However, the PCR profiles of C. urealyticum and C. diphtheriae biotype intermedius were similar. Nevertheless, biochemical tests, such as nitrate reduction and urease production, allow workers to distinguish $C$. urealyticum from $C$. diphtheriae biotype intermedius (16). Moreover, knowledge of clinical symp- toms may help the microbiologists to identify these two species and to alleviate ambiguities.

In conclusion, our study of the length polymorphisms of the 16S-23S rDNA spacer regions by PCR-mediated amplification with primers $\mathrm{G} 1$ and $\mathrm{L} 1$ (26) showed that $C$. renale, $C$. urealyticum, C. diphtheriae, C. ulcerans, C. pseudodiphtheriticum, and $C$. kutscheri are homogeneous taxa, while C. amycolatum, C. striatum, C. minutissimum, and $C$. jeikeium are heterogeneous. Analysis of these length polymorphisms may also be used for identification of strains at the species level in most cases. It has to be emphasized that this method allows workers to discriminate $C$. amycolatum, $C$. striatum, $C$. minutissimum, and $C$. xerosis, which are frequently confused in clinical laboratories. Consequently, this method, which is easy to perform in clinical laboratories since no restriction analysis of PCR products is necessary and agarose gel electrophoresis results in sufficient resolution for differentiation, is a useful tool for microbiologists. Identification of corynebacteria to the species level is worthwhile in order to detect unsuspected species, to identify previously undescribed species, and to ascribe potential pathogenicity to species thought to be nonpathogenic (47).

\section{ACKNOWLEDGMENTS}

We thank P. Riegel for providing $C$. jeikeium strains and C. Bollet for helpful discussions.

\section{REFERENCES}

1. Bacot, C. M., and R. H. Reeves. 1991. Novel tRNA gene organization in the 16S-23S intergenic spacer of the Streptococcus pneumoniae rRNA gene cluster. J. Bacteriol. 173:4234-4236.

2. Barreau, C., F. Bimet, M. Kiredjian, N. Rouillon, and C. Bizet. 1993. Comparative chemotaxonomic studies of mycolic acid-free coryneform bacteria of human origin. J. Clin. Microbiol. 31:2085-2090.

3. Barry, T., G. Colleran, M. Glennon, L. K. Dinican, and F. Gannon. 1991 The $16 \mathrm{~S} / 23 \mathrm{~S}$ ribosomal spacer region as a target for DNA probes to identify eubacteria. PCR Methods Appl. 1:51-62.

4. Brosius, J., T. J. Dull, D. D. Sleeter, and H. F. Noller. 1981. Gene organization and primary structure of a ribosomal RNA operon from Escherichia coli. J. Mol. Biol. 148:107-127.

5. Cartwright, C. P., F. Stock, S. E. Beekmann, E. C. Williams, and V. J. Gill. 1995. PCR amplification of rRNA intergenic spacer regions as a method for epidemiologic typing of Clostridium difficile. J. Clin. Microbiol. 33:184-187.

6. Centers for Disease Control. 1995. Diphtheria epidemic-new independent states of the former Soviet Union, 1990-1994. Morbid. Mortal. Weekly Rep. 44:177-181.

7. Clarridge, J. E., and C. A. Spiegel. 1995. Corynebacterium and miscellaneous irregular gram-positive rods, Erysipelothrix, and Gardnerella, p. 357-378. In P. R. Murray, E. J. Baron, M. A. Pfaller, F. G. Tenover, and R. H. Yolken (ed.), Manual of clinical microbiology, 6th ed. American Society for Microbiology, Washington, D.C.

8. Collins, M. D., and C. S. Cummins. 1986. Genus Corynebacterium, Lehmann and Neumann 1896, 350, p. 1266-1276. In P. H. A. Sneath, N. S. Mair, M. E. Sharpe, and J. G. Holt (ed.), Bergey's manual of systematic bacteriology, vol. 2. The Williams \& Wilkins Co., Baltimore, Md.

9. Coyle, M. B., N. B. Groman, J. O. Russell, J. P. Harnisch, M. Rabin, and K. K. Holmes. 1989. The molecular epidemiology of three biotypes of Corynebacterium diphtheriae in the Seattle outbreak, 1972-1982. J. Infect. Dis. 159:670-679.

10. Coyle, M. B., and B. A. Lipsky. 1990. Coryneform bacteria in infectious diseases: clinical and laboratory aspects. Clin. Microbiol. Rev. 3:227-246.

11. De Briel, D., F. Couderc, P. Riegel, F. Jehl, and R. Minck. 1992. High performance liquid chromatography of corynomycolic acids as a tool in identification of Connebacterium species and related organisms. J. Clin. Microbiol. 30:1407-1417.

12. De Zoysa, A., A. Efstratiou, R. C. George, M. Jahkola, J. Vuopio-Varkila, S Deshevoi, G. Tseneva, and Y. Rikushin. 1995. Molecular epidemiology of Corynebacterium diphtheriae from northwestern Russia and surrounding countries studied by using ribotyping and pulsed-field gel electrophoresis. J. Clin. Microbiol. 33:1080-1083.

13. Estrangin, E., B. Thiers, and Y. Peloux. 1987. Apport des microméthodes et de l'analyse en chromatographie en phase gazeuse des acides carboxyliques issus de la fermentation du glucose dans l'identification des corynébactéries. Ann. Biol. Clin. 45:285-289.

14. Freney, J., M. T. Duperron, C. Courtier, W. Hansen, F. Allard, J. M. Boeufgras, D. Monget, and J. Fleurette. 1991. Evaluation of API Coryne in com- 
parison with conventional methods for identifying coryneform bacteria. J. Clin. Microbiol. 29:38-41.

15. Funke, G., P. A. Lawson, K. A. Bernard, and M. D. Collins. 1996. Most Corynebacterium xerosis strains identified in the routine clinical laboratory correspond to Corynebacterium amycolatum. J. Clin. Microbiol. 34:11241128.

16. Funke, G., A. von Graevenitz, J. E. Clarridge, and K. A. Bernard. 1997. Clinical microbiology of coryneform bacteria. Clin. Microbiol. Rev. 10:125159.

17. Garnier, T., B. Canard, and S. T. Cole. 1991. Cloning, mapping, and molecular characterization of the rRNA operons of Clostridium perfringens. J. Bacteriol. 173:5431-5438.

18. Gavin, S. E., R. B. Leonard, A. M. Briselden, and M. B. Coyle. 1992. Evaluation of the rapid CORYNE identification system for Corynebacterium species and other coryneforms. J. Clin. Microbiol. 30:1692-1695.

19. Gruner, E., P. L. F. Zuber, G. Martinetti Lucchini, A. von Graevenitz, and M. Altwegg. 1992. A cluster of non-toxigenic Corynebacterium diphtheriae infections among Swiss intravenous drug abusers. Med. Microbiol. Lett. 1:160-167.

20. Gürtler, V., and V. A. Stanisich. 1996. New approaches to typing and identification of bacteria using the $16 \mathrm{~S}-23 \mathrm{~S}$ rDNA spacer region. Microbiology 142:3-16.

21. Hamour, A. A., A. Efstratiou, R. Neill, and E. M. Dunbar. 1995. Epidemiology and molecular characterisation of toxigenic Corynebacterium diphtheriae var. mitis from a case of cutaneous diphtheria in Manchester. J. Infect. 31:153-157.

22. Harasawa, R., H. Mizusawa, K. Nozawa, T. Nakagawa, K. Asada, and I. Kato. 1993. Detection and tentative identification of dominant mycoplasma species in cell cultures by restriction analysis of the 16S-23S rRNA intergenic spacer regions. Res. Microbiol. 144:489-493.

23. Hindmarch, J. M., J. T. Magee, M. A. Hadfield, and B. I. Duerden. 1990. A pyrolysis-mass spectrometry of Corynebacterium spp. J. Med. Microbiol. 31: $137-149$.

24. Hookey, J. V., R. J. Birtles, and N. A. Saunders. 1995. Intergenic 16S rRNA gene (rDNA)-23S rDNA sequence length polymorphisms in members of the family Legionellaceae. J. Clin. Microbiol. 33:2377-2381.

25. Jackman, P. J. H., D. G. Pitcher, S. Pelczynska, and P. Borman. 1987. Classification of corynebacteria associated with endocarditis (group JK) as Corynebacterium jeikeium sp. nov. Syst. Appl. Microbiol. 9:83-90.

26. Jensen, M. A., J. A. Webster, and N. Straus. 1993. Rapid identification of bacteria on the basis of polymerase chain reaction-amplified ribosomal DNA spacer polymorphisms. Appl. Environ. Microbiol. 59:945-952.

27. Jenum, P. A., V. Skogen, E. Danilova, A. Eskild, and H. Sjursen. 1995. Immunity to diphtheria in northern Norway and northwestern Russia. Eur. J. Clin. Microbiol. Infect. Dis. 14:794-798.

28. Jones, D., and M. D. Collins. 1987. Irregular, nonsporing gram-positive rods, p. 1267-1434. In P. H. A. Sneath, N. S. Mair, M. E. Sharpe, and J. G. Holt (ed.), Bergey's manual of systematic bacteriology, vol. 2. The Williams \& Wilkins Co., Baltimore, Md.

29. Kostman, J. R., T. D. Edlind, J. J. LiPuma, and T. L. Stull. 1992. Molecular epidemiology of Pseudomonas cepacia determined by PCR ribotyping. J. Clin. Microbiol. 30:2084-2087.

30. Lortholary, O., A. Buu-Hoï, L. Gutmann, and J. Acar. 1993. Corynebacterium diphtheriae endocarditis in France. Clin. Infect. Dis. 17:1072-1074.

31. Loughney, K., E. Lund, and J. E. Dahlberg. 1982. tRNA genes are found between the 16S and 23S rRNA genes in Bacillus subtilis. Nucleic Acids Res. 10:1607-1624.

32. Lystad, A. 1992. Diphtheria in Finnmark. Communicable Dis. Rep. (Norway) 20:53. (In Norwegian.)

33. Maniatis, T., E. F. Fritsch, and J. Sambrook. 1982. Molecular cloning: a laboratory manual. Cold Spring Harbor Laboratory, Cold Spring Harbor, N.Y.

34. Minnikin, D. E., L. Alshamaony, and M. Goodfellow. 1975. Differentiation of Mycobacterium, Nocardia, and related taxa by thin-layer chromatography analysis of whole organism methanolysates. J. Gen. Microbiol. 88:200-204.

35. Pappenheimer, A. M., Jr., and J. R. Murphy. 1983. Studies on the molecular epidemiology of diphtheria. Lancet ii:923-926.

36. Pitcher, D., A. Johnson, F. Allerberger, N. Woodford, and R. George. 1990 An investigation of nosocomial infection with Corynebacterium jeikeium in surgical patients using a ribosomal RNA gene probe. Eur. J. Clin. Microbiol. Infect. Dis. 9:643-648.

37. Poilane, I., F. Fawaz, M. Nathanson, P. Cruaud, T. Martin, A. Collignon, and J. Gaudelus. 1995. Corynebacterium diphtheriae osteomyelitis in an immunocompetent child: a case report. Eur, J. Pediatr. 154:381-383.

38. Rappuoli, R., M. Perugini, and E. Falsen. 1988. Molecular epidemiology of the 1984-1986 outbreak of diphtheria in Sweden. N. Engl. J. Med. 318:12-14.

39. Riegel, P., D. De Briel, G. Prévost, F. Jehl, and H. Monteil. 1994. Genomic diversity among Corynebacterium jeikeium strains and comparison with biochemical characteristics and antimicrobial susceptibilities. J. Clin. Microbiol. 32:1860-1865

40. Riegel, P., P. A. D. Grimont, D. De Briel, E. Ageron, F. Jehl, M. Pelegrin, H. Monteil, and R. Minck. 1992. Connebacterium group D2 ("Corynebacterium urealyticum") constitutes a new genomic species. Res. Microbiol. 143:307313.

41. Riegel, P., R. Ruimy, D. De Briel, G. Prévost, F. Jehl, R. Christen, and H. Monteil. 1995. Taxonomy of Corynebacterium diphtheriae and related taxa, with recognition of Corynebacterium ulcerans sp. nov. nom. rev. FEMS Microbiol. Lett. 126:271-276.

42. Soto, A., D. G. Pitcher, and F. Soriano. 1991. A numerical analysis of ribosomal RNA gene patterns for typing clinical isolates of Corynebacterium group D2. Epidemiol. Infect. 107:263-272.

43. Tiley, S. M., K. R. Kociuba, L. G. Heron, and R. Muro. 1993. Infective endocarditis due to nontoxigenic Corynebacterium diphtheriae: a report of seven cases and review. Clin. Infect. Dis. 16:271-275.

44. Van Bosterhaut, B., R. Cuvelier, E. Serruys, F. Pouthier, and G. Wauters. 1992. Three cases of opportunistic infection caused by propionic acid producing Corynebacterium minutissimum. Eur. J. Microbiol. Infect. Dis. 11: 628-631.

45. Vaneechoutte, M., P. Riegel, D. De Briel, G. Verschraegen, A. D. Rouck, and G. Claeys. 1995. Evaluation of the applicability of amplified rDNA-restriction analysis (ARDRA) to identification of species of the genus Corynebacterium. Res. Microbiol. 146:633-641.

46. Vilgalys, R., and M. Hester. 1990. Rapid genetic identification and mapping of enzymatically amplified ribosomal DNA from several Cryptococcus species. J. Bacteriol. 172:4238-4246.

47. von Graevenitz, A., V. Pünter, E. Gruner, G. E. Pfyffer, and G. Funke. 1994 Identification of coryneform and other gram-positive rods with several methods. APMIS 102:381-389.

48. Von Hunolstein, C., A. Efstratiou, R. L. Valle, G. Gentili, S. Pestalozza, M. T. Mascellino, R. Rappuoli, G. Orefici, and A. Cassone. 1995. An imported fatal case of diphtheria in Italy. Eur. J. Microbiol. Infect. Dis. 14:828-829.

49. Wauters, G., A. Driessen, E. Ageron, M. Janssens, and P. A. D. Grimont. 1996. Propionic acid-producing strains previously designated as Corynebacterium xerosis, $C$. minutissimum, $C$. striatum, and $\mathrm{CDC}$ group $\mathrm{I}_{2}$ and group $\mathrm{F}_{2}$ coryneforms belong to the species Corynebacterium amycolatum. Int. J. Syst. Bacteriol. 46:653-657.

50. Zinkernagel, A. S., A. von Graevenitz, and G. Funke. 1996. Heterogeneity within Corynebacterium minutissimum strains is explained by misidentified Corynebacterium amycolatum strains. Am. J. Clin. Pathol. 106:378-383. 